\title{
PEMANFAATAN MODEL 3 DIMENSI UNTUK INFORMASI WISATA KOTA MEDAN (Studi Kasus: Kawasan Medan Heritage)
}

\author{
Joko Bintarto \\ Program Studi Desain Komunikasi Visual, Fakultas Seni dan Desain, \\ Universitas Potensi Utama \\ e-mail: jbintarto@gmail.com
}

\begin{abstract}
ABSTRAK
Kota Medan memerlukan informasi kawasan wisata dalam bentuk visualisasi Model 3 dimensi. Model 3 dimensi sangat penting untuk memberikan informasi keadaan wilayah dan fasilitas yang ada di tempat wisata serta untuk mempersiapkan diri dalam melakukan wisata. Proses penelitian melibatkan proses perancangan yaitu pembuatan media informasi wisata kota medan dengan merancang model 3 dimensi pada kawasan wisata Medan Heritage, dimana pada kawasan tersebut terdapat bangunan bersejarah yang memiliki nilai historis tinggi yang dapat memberikan ciri khas dan keunikan kota Medan dan membangun citra wisata heritage. Metode penelitian yang digunakan dalam penelitian ini adalah metode Desain (Desain Komunikasi Visual) melalui tahapan Analisis, Sintetis dan Evaluasi. Hasil dari penelitian ini adalah karya model 3D kawasan Medan Heritage sebagai kawasan wisata dengan bangunan bersejarah di kota medan seperti Istana Maimun, Masjid Raya Al Mashun, PT. PP London Sumatera, dan Kantor Pos agar seperti aslinya.
\end{abstract}

Kata Kunci: Model 3D, Kawasaan Medan Heritage, informasi Wisata

\begin{abstract}
Medan City requires information on tourist areas in the form of a 3-dimensional model visualization. The 3-dimensional model is very important to provide information on the state of the area and existing facilities at tourist attractions and to prepare for tourism. The research process involved the design process, namely the creation of the Medan city tourism information media by designing a 3dimensional model in the Medan Heritage tourist area, where in the area there are historical buildings that have high historical value that can give the characteristics and uniqueness of the city of Medan and build a heritage tourism image. The research method used in this research is the design method (Visual Communication Design) through the stages of Analysis, Synthesis and Evaluation. The result of this research is the work of a 3D model of the Medan Heritage area as a tourist area with historical buildings in the city of Medan such as the Maimun Palace, Al Mashun Grand Mosque, PT. PP London Sumatera, and Post Office to be like the original.
\end{abstract}

Keywords: $3 D$ model, Kawasa Medan Heritage, tourism information

\section{PENDAHULUAN}

Kota Medan juga memiliki sejarah panjang yang dapat dilihat dari peninggalan peninggalan bersejarah, seperti bangunan-bangunan tua serta tugu-tugu yang menyimpan makna akan warisan sejarah serta nilai religi yang menjadi warisan budaya Kota Medan.

Informasi merupakan hal yang diperlukan sebelum wisatawan dating ke tempat wisata. Umumnya wisatawan bisa memperoleh informasi tersebut dari buku petunjuk maupun 
media internet. Informasi yang lengkap akan memberikan kesempatan kepadawisatawan untuk mempersiapkan diri sebaik-baiknya (Leonard. 2013 dalam bintarto).

Model obyek dalam bentuk tiga dimensi (3D) merupakan salah satu bentuk pemberian informasi yang menarik. Obyek 3D dapat dilihat dari berbagai arah sehingga wisatawan bisa memperoleh informasi secara visual. Hal ini menjadi lebih menarik karena kombinasi antara teks dan model 3D memberikan informasi lebih luas.

Wali Kota Medan, Drs. H. T. Dzulmi Eldin, S.M. Si., dalam Seminar Hasil Penelitian Bangunan Bersejarah/Heritage yang Layak Direnovasi/Dipelihara, menyatakan "Bangunan warisan budaya di Medan merupakan aset yang tidak ternilai dan tidak dapat ditemukan lagi di masa mendatang. Jika bangunan itu tidak dilestarikan maka Medan kehilangan identitasnya" (Pemerintah Medan, 2020 dalam bintarto).

Terkait informasi wisata di kota Medan, penelitian ini memilih kawasan Medan Heritage yang meliputi Istana Maimin, Masjid Raya Al Mashun, PT PP London Sumatera, dan Kantor Pos menjadi studi kasus dalam pemanfaatan model 3 Dimensi untuk informasi wisata kota Medan. Sehubungan dengan itulah dibuat model 3 Dimensi dengan tujuan memberikan informasi yang jelas dan lengkap dengan membuat bentuk visual kawasan Medan Heritage yang hampir menyerupai aslinya.

\section{METODE PENELITIAN}

Dalam proses penelitian melibatkan proses perancangan yaitu pembuatan media informasi wisata kota medan dengan model 3 dimensi. Zainudin mengatakan metode desain komunikasi visual sebagai metode penelitian desain yang memuat prosedur: analisis, sintesis dan evaluasi. Dalam proses analisis menggunakan penelitian kualitatif dalam mengenali dan menganalisa masalah berdasarkan pengumpulan data. Selanjutnya sintesis merupakan proses menemukan dan mendefinisikan konsep desain yang berisi solusi permasalahan yang sudah dilakukan dalam proses kreatif yang mengeksplorasi ide-ide kreatif dan mengatur elemen-elemennya dalam akomposisi yang harmonis dan estetis. Evaluasi dilakukan dengan mempresentasikan produk yang dihasilkan untuk memverifikasi lebih lanjut berdasarkan tentang identifikasi masalah dan tujuan yang ingin dicapai.Kebutuhan terhadap pembuatan media informasi wisata kota Medan melalui model 3 dimensi menggunakan pendekatan desain komunikasi visual, dimana Desain Komunikasi Visual menurut said dan Cahyadi adalah bidang ilmu yang bertujuan untuk menemukan solusi (pemecahan masalah) di ranah komunikasi visual yang metodologinya dilakukan melalui proses sistematis, yaitu dengan pengolahan atau penataan elemen visual menjadi bahasa visual yang menarik minat atau perhatian, memiliki nilai estetis dan mudah dipahami, dimana "bahasa visual" adalah implementasi dari isi pesan atau informasi yang dikomunikasikan kepada khalayak sasaran (Said dan Cahyadi (2017) dalam bintarto). Observasi yaitu melakukan pengamatan secara lansung ke obyek penelitian untuk melihat dari dekat kegiatan yang akan dilakukan (Riduwan, 2010 dalam bintarto). Tahapan ini melakukan pengamatan langsung terhadap obyek penelitian pada kawasan Medan Heritage seperti Istana Maimun, Masjid Raya Al Mashun, PT PP London Sumatera, dan Kantor Pos. Selain itu, metode perancangan yang akan dilakukan dalam penelitian ini dapat dilihat ( gambar 1 ). 


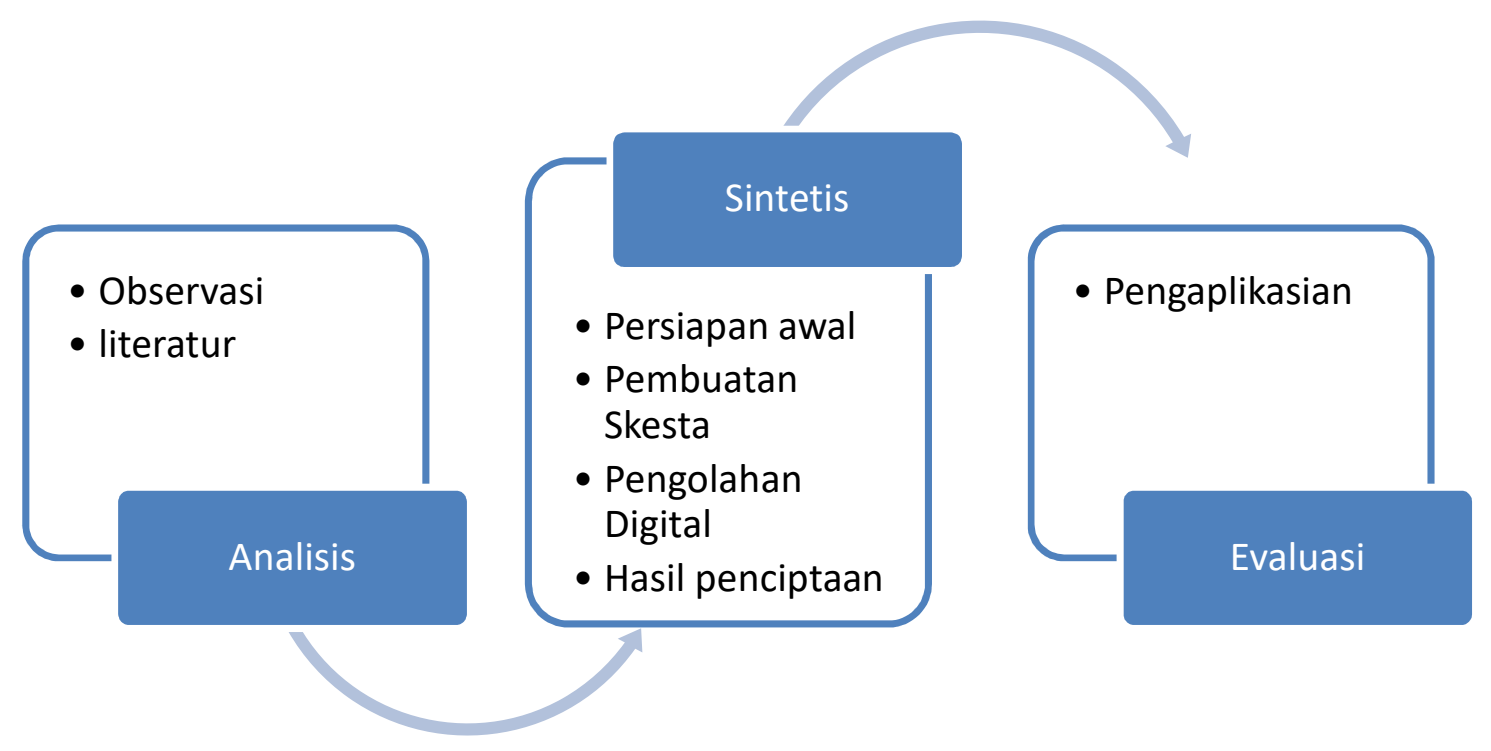

Gambar 1. Bagan metode penelitian desain (Desain Komunikasi Visual) Zainudin (dalam Azis dan Cahyadi, 2017) yang diterapkan pada perancangan media informasi wisata kota Medan melalui model 3 dimensi.

( Sumber: Dokumen,peneliti )

Tahapan analisis yang bertujuan untuk menganalisis masalah melalui pengumpulan data, data yang dikumpulkan adalah data primer berupa hasil observasi, dan data sekunder dengan melakukan studi literatur. Selanjutnya tahapan sintesis merupakan tahapan mencari dan mengembangkan model dengan melakukan teknik rancangan model 3 dimensi meliputi persiapan awal dalam menentukan ide kreatif pada model 3 dimensi selanjutnya melakukan tahapan pembuatan skesta obyek penelitian secara manual serta penggunaan aplikasi komputer dalam pengolahan digital seperti Google SketchUp. Terakhir adalah tahap evaluasi yaitu pengaplikasian model 3 dimensi pada media digital yaitu video animasi 3 dimensi mengunakan platform youtube.

\section{PEMBAHASAN}

Informasi merupakan hal yang dibutuhkan sebelum wisatawan datang ke tempat wisata. Umumnya wisatawan bisa mendapatkan informasi tersebut dari media cetak seperti brosur, poster, buku petunjuk, dan juga media internet. Informasi yang lengkap akan memberikan kesempatan kepada wisatawan untuk mempersiapkan diri sebaik-baiknya.

Menurut Hall \& McArther (1996), dalam bukunya Heritage Management, definisi heritage terdiri dari warisan budaya tak benda (intangible) dan warisan budaya benda (tangible). Warisan budaya kebendaan (tangible) yaitu seperti arsitektur bangunan, monumen, rumah ibadah, alat musik, baju adat, peralatan, kerajinan tangan, dan warisan budaya yang tidak berwujud kebendaan (intangible) yaitu berupa berbagi atribut kelompok atau masyarakat, seperti norma, tata nilai, cara hidup, dan folklore.

Kawasan Heritage Medan dalam hal ini merupakan warisan budaya. Warisan budaya perlu dilestarikan dan dipelihara juga perlu dimanfaatkan, seperti yang dinyatakan oleh Wali Kota Medan Dzulmi Eldin bahwa "Bangunan warisan budaya di Medan merupakan aset yang tidak ternilai dan tidak dapat ditemukan lagi di masa mendatang. Jika bangunan itu 
tidak dilestarikan maka Medan kehilangan identitasnya" (Pemerintah Medan, 2020 dalam bintarto). Kota Medan memiliki beberapa kawasan wisata yang dapat diunggulkan khususnya kawasan Medan Heritage yang merupakan kawasan dengan gedung-gedung arsitektur bersejarah.

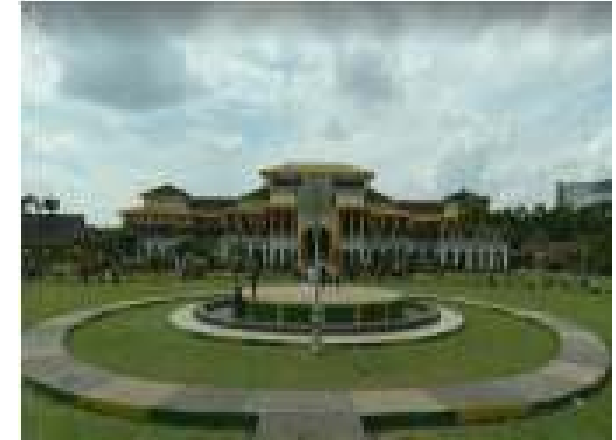

(a) Istana Maimun

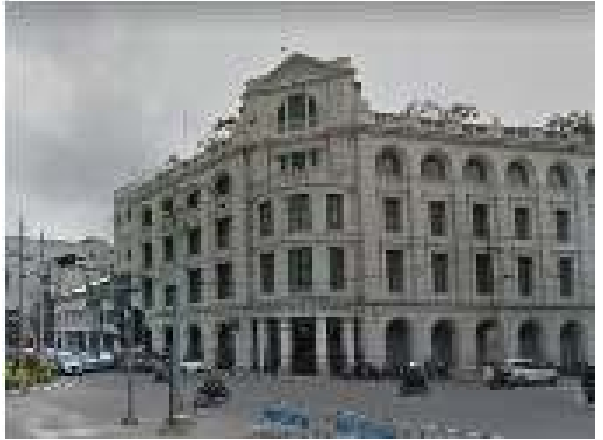

(c) PT PP London Sumatera

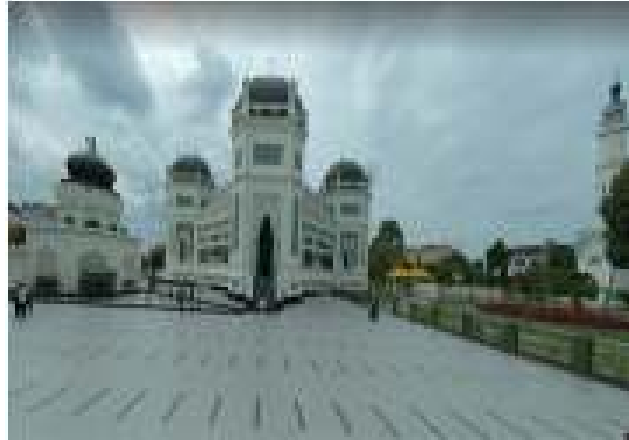

(b) Masjid Raya Al Mashun

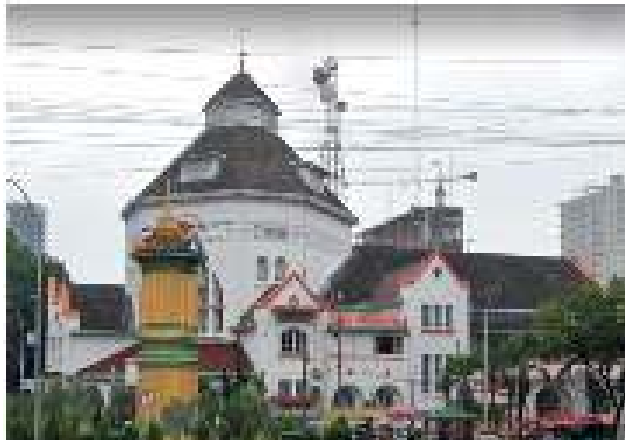

(d) Kantor Pos Medan

Gambar 2. Bangunan Warisan Budaya Kota Medan.

( Sumber: Dokumen,peneliti )

Ahmed telah mengulas bahwa informasi penting bagi wisatawan dapat lebih baik dengan media gambar (Ahmed, Z.U. 1996). Berkaitan dengan hal ini Ladkin (2000), menyelidiki bagaimana perilaku wisatawan terutama yang mau memilih daerah-daerah wisata menggunakan sumber informasi teks dan gambar. Berdasarkan hal tersebut, penggunaan model 3 dimensi sebagai media informasi dinilai dapat menyajikan sesuatu yang tampak nyata sehingga lebih dapat menarik minat khalayak sasaran, dalam hal ini Yim dkk. ( 2004 ) menyatakan bahwa obyek 3D merupakan media penyampaian informasi yang efektif. Model obyek dalam bentuk tiga dimensi (3D) merupakan salah satu bentuk yang dapat dilihat dari berbagai arah sehingga wisatawan bisa memperoleh informasi secara visual serta kombinasi antara teks dan model 3D memberikan informasi lebih luas.

Penelitian yang terkait adalah tugas akhir Amrikahfi Ginting yang berjudul "Animasi 3D Menggunakan Augmented Reality Sebagai Media Pengenalan Warisan Budaya Kota Medan Kawasan Kota Matsum Dan Kesawan“ tahun 2018. Dalam penelitian tersebut bentuk model 3D menggunakan Augmented Reality, dimana obyek 3D akan tampil pada layar virtual nyata secara real-time. Augmented Reality nyata, dan terdapat integrasi antar benda dalam tiga dimensi, yaitu benda maya terintegrasi dalam dunia nyata. Objek 3D yang ditampilkan Kawasan Kota tua di Medan seperti Masjid Raya Al Mashun, London Sumatera, Istana Maimun, PAM tirtanadi, Kantor Pos Medan dapat dilihat (gambar 3). 


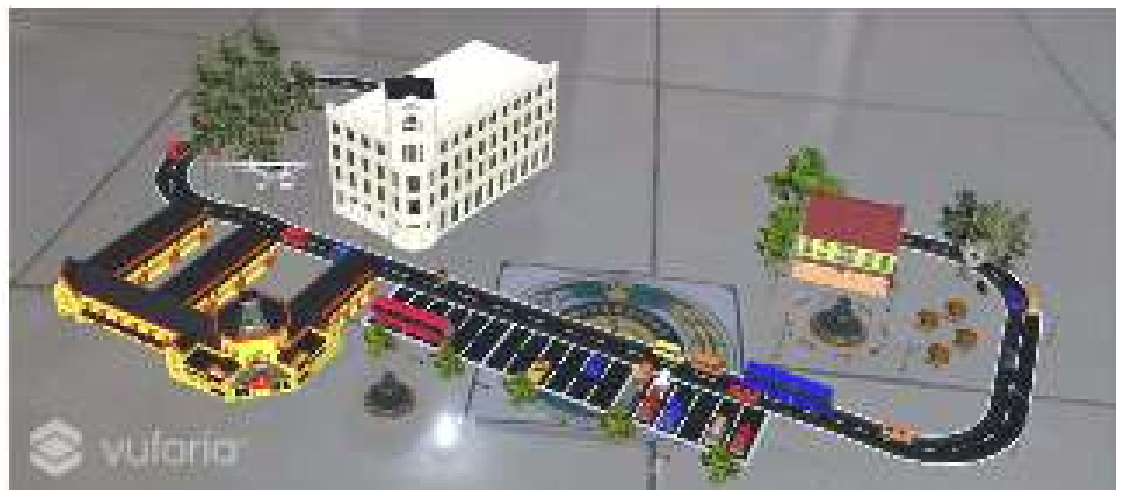

Gambar 3. Tampilan Scene Kota Matsum pada Layar Virtual AR (Sumber : Dokumentasi Amrikahfi, 2018)

SketchUp merupakan perangkat lunak yang dapat digunakan untuk memodelkan obyek 2 dimensi maupun 3 dimensi . Beberapa fitur yang dipakai dalam pengolahan digital menggunakan Google SketchUp diantaranya Modelling $3 D$ adalah proses mengembangkan representasi matematis dari setiap permukaan obyek tiga dimensi (baik mati ataupun hidup) melalui perangkat lunak khusus. Model ini juga dapat secara fisik dibuat menggunakan perangkat percetakan 3 dimensi (Jostonchoniv dan Windarto, 2013 dalam bintarto). Proses texturing adalah proses pembuatan dan pemberian warna dan material pada obyek yang telah selesai dimodelkan dengan tujuan untuk menunjukkan kesan nyata. Pemberian material pada obyek 3D akan mendefiniskan rupa dan jenis bahan dari obyek 3D (Handayani, 2011 dalam bintarto).

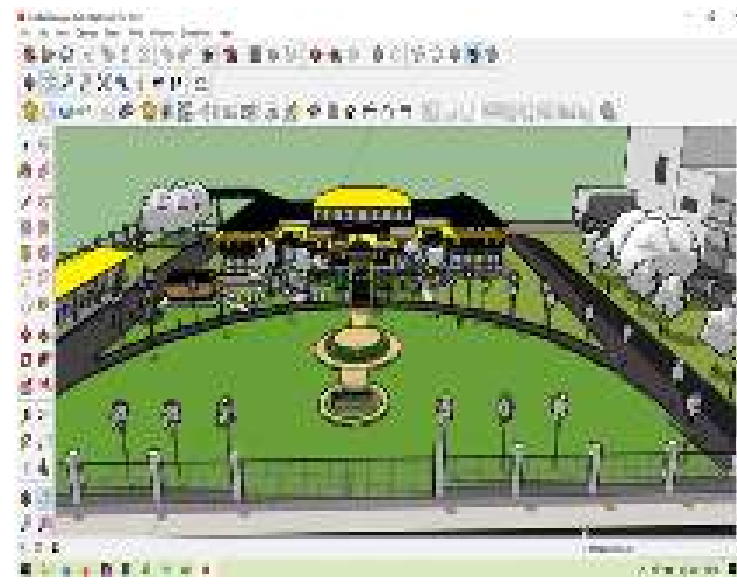

(a) Model 3D Istana Maimun

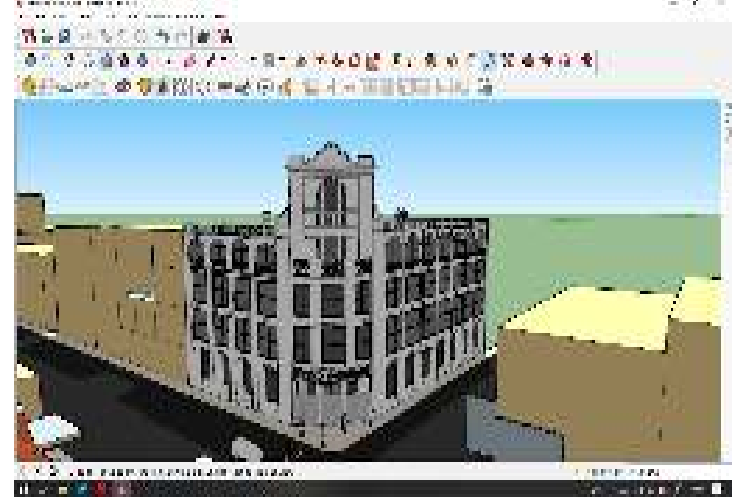

(c) Model 3D PT PP London Sumatera

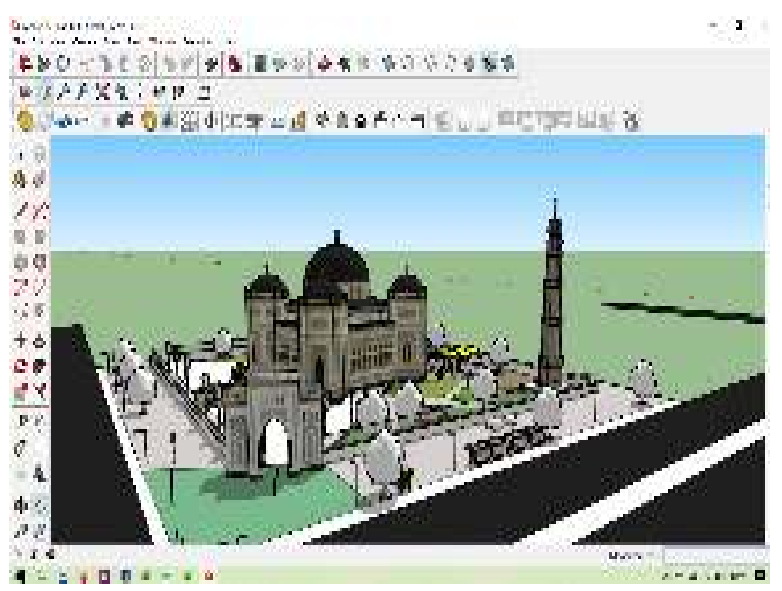

(b) Model 3D Masjid Raya Al Mahsun

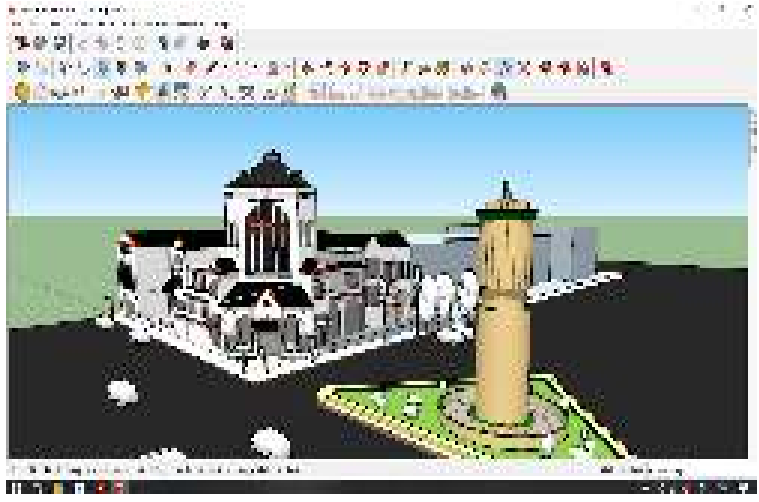

(d) Model 3D Kantor Pos Medan 
Gambar 4. Model 3 Dimensi dengan tekstur pada Bangunan Warisan Budaya Kota Medan ( Sumber: bintarto,2020)

Rendering 3D merupakan proses untuk membentuk sebuah gambar dari sebuah model berisi data geometri, titik pandang, tekstur, dan cahaya yang diperlukan untuk membuat gambar yang utuh (Ginting, Amrikahfi. 2018 dalam bintarto ). Rendering 3D merupakan proses yang sangat penting dan telah digunakan untuk berbagai macam pengguna, seperti program permainan komputer, efek special pada film, dan program simulasi (Jostonchoniv dan Windarto, 2013). Proses rendering 3 dimensi menggunakan fitur enscape yang merupakan fitur tambahan pada SkecthUp yang dapat di download pada alamat website resminya (Enscape Daring). Fitur ini berguna untuk proses rendering 3 dimensi yang menghasilkan tampilan model 3 dimensi hampir merupai aslinya, dapat dilihat (gambar 5).
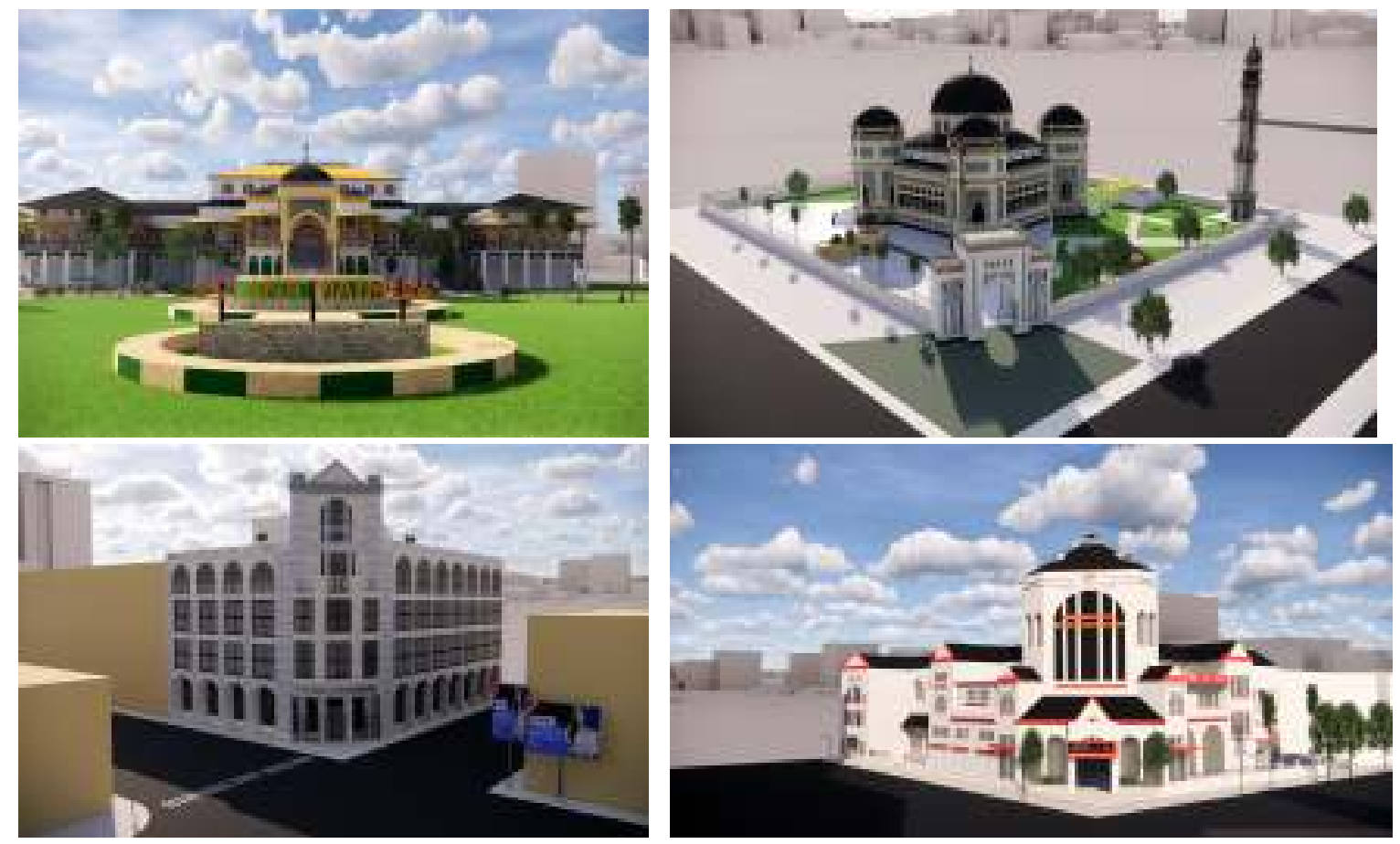

Gambar 5. Rendering 3 Dimensi pada Bangunan Warisan Budaya Kota Medan

( Sumber: bintarto,2020)

Tahapan terakhir adalah implementasi model 3 dimensi yang sudah dibuat ke dalam media digital berupa media animasi 3 dimensi. Proses implementasi model 3 dimensi ke dalam media animasi 3 dimensi dapat dilihat melalui platform video youtube pada link https://www.youtube.com/watch? $\mathrm{v}=$ YlpIxBLBzk dengan subjek Video Animasi 3D kawasan Medan Heritage Daring. Tujuan pengapilkasian model 3 dimensi dalam media animasi 3 dimensi adalah memberikan informasi wisata kota medan dalam bentuk media promosi wisata yang dapat memberikan pemahaman yang lebih baik bagi calon wisatawan.

\section{KESIMPULAN}

Penelitian ini menggunakan metode desain komunikasi visual dalam pembuatan model 3 dimensi dalam memberikan informasi wisata kota Medan dengan mengambil studi kasus 
pada kawasan Medan Heritage. Tahapan-tahapan metode desain membagi proses-proses penelitian dan perancangan secara sistematis dari tahap Analisis, Sintetis dan Evaluasi, dimana semua proses perancangan melalui tahapan ini, sehingga tahapan penelitian dan perancangan dapat diimplementasikan secara sistematis.

Tahapan analisis yang bertujuan untuk menganalisis masalah melalui pengumpulan data, data yang dikumpulkan adalah data primer berupa hasil observasi, dan data sekunder dengan melakukan studi literatur. Selanjutnya tahapan sintesis merupakan tahapan mencari dan mengembangkan model dengan melakukan teknik rancangan model 3 dimensi meliputi persiapan awal dalam menentukan ide kreatif pada model 3 dimensi selanjutnya melakukan tahapan pembuatan skesta obyek penelitian secara manual serta penggunaan aplikasi komputer dalam pengolahan digital seperti Google SketchUp. Terakhir adalah tahap evaluasi yaitu pengaplikasian model 3 dimensi pada media digital yaitu video animasi 3 dimensi mengunakan platform youtube.

Penggunaan model 3D dapat meningkatkan pemahaman terhadap informasi bagi calon wisatawan serta memberikan informasi mengenai keadaan daerah wisata. model 3 dimensi daerah wisata yang dipromosikan untuk membuat lebih menarik dan memberikan informasi lebih banyak. Diharapkan hasil penelitian ini dapat dijadikan sebagai referensi dan acuan untuk berbagai pihak yang berkepentingan mempromosikan Kota Medan terutama pihak Pemerintah Kota Medan.

\section{DAFTAR PUSTAKA}

\section{Buku :}

[1] Ahmed, Z.U. 1996. The Need for the Identification of the Constituents of a Destination's Tourist Image: A Promotion Segmentation Perspective., Vol.14 No.1, Journal of Professional Services Marketing.

[2] J.F. Fleron. 2009, Google SketchUp: A Powerful Tool for Teaching, Learning and Applying Geometry. Westfled: Westfled State College.

[3] Hall, C. M., \& McArthur, S. (1996). Heritage Management: An Introductory Framework. Auckland: Oxford University Press.

\section{Jurnal :}

[4] Bintarto, 2020, Pemanfaatan video Animasi 3D sebagai Media Promosi Wisata Kota Medan. Vol.9 No.1, Jurnal Visualita.

[5] Ladkin, A. 2000, Research into Consumer Behaviour and Value Systems of Ecotourists. Vol.2 No.3, The International Journal of Tourism Research.

[6] Said, Abdul Azis dan Cahyadi, Dian (2017). Design Of Learning Media with Visual Communication Design Methodology. International Conference on Education, Science, Art and Technology. ISSN 2581-1886. Vol 1, No. 1. Hal. 1-7.

[7] Yim, M.Y.C., Cicchirillo, V.J., Drumwright, M.E. 2012. THE Impact of Stereoscopic Three-Dimensional (3-D) Advertising: The Role of Presence in Enhancing Advertising Effectiveness. Vol.41 No.2, Journal of Advertising. 


\section{Prosiding Seminar :}

[8] Leonard. 2013. Pemanfaatan Model 3D untuk Penyebaran Informasi dalam Industri Pariwisata. Proceeding Seminar Inovasi Teknologi dan Rekayasa Industri, Universitas Andalas, Padang, 2 Juli 2013

\section{Skripsi :}

[9] Ginting, Amrikahfi. 2018. Animasi 3D Menggunakan Augmented Reality Sebagai Media Pengenalan Warisan Budaya Kota Medan Kawasan Kota Matsum dan Kesawan.Skripsi.Universitas Sumatera Utara.

\section{Sumber Online/Internet :}

[8] Enscape Daring. (n.d.). Diambil 29 September 2020, dari https://enscape3d.com/do

[9] Pemerintah Medan (2020). Wali Kota Buka Seminar Akhir Hasil Penelitian Bangunan Bersejarah di Medan. Pemkomedan.go.id. Diakses 10 Febuari 2021 . wnload/. 